\title{
Entre Segurança e Identidades: Europa e Rússia no Combate ao Estado Islâmico
}

\author{
João Paulo Alves Assêncio ${ }^{1}$ e Guilherme Adams G. Sales ${ }^{2}$
}

\begin{abstract}
Resumo:
O presente artigo trata sobre a influência de fatores culturais e identitários em conflitos contemporâneos. Especificamente, o terrorismo é abordado como uma modalidade de conflito que toma a forma atual, fortemente influenciada por embates entre culturas distintas que fortalecem identidades coletivas internalizadas por indivíduos membros de um mesmo agrupamento. Utilizam-se argumentos que têm como base a ideia de construção social da realidade, no sentido de tentar explanar os questionamentos levantados. Este presente artigo busca confirmar a hipótese de que as percepções mútuas dos atores, baseada nos fatores sociais considerados, são determinantes para definir relações de hostilidades. Partindo das argumentações de Huntington, Wendt, Castells, Waltz, Kissinger, entre outros, são apresentadas bases conceituais e teóricas que oferecem entendimento para a questão abordada. Para tanto, discorre-se sobre a relação de fatores culturais nas novas dinâmicas de conflito do pós-guerra fria, argumentando acerca do surgimento do Estado Islâmico e das iniciativas contra terroristas russas e europeias. Além disso, serão analisados também como os aspectos culturais específicos dos atores se relacionam.
\end{abstract}

Palavras-chave: Choque de Civilizações; Terrorismo; Relações Internacionais.

\section{Abstract:}

This article deals with the influence of cultural and identity factors in contemporary conflicts. Specifically, terrorism is approached as a form of conflict which is strongly influenced by clashes between distinct cultures that strengthen collective identities internalized by individuals members of the same grouping. We argue that this identities are founded on the idea of social construction of reality, in the sense of trying to explain the questions raised socially. We aim to confirm the hypothesis that the mutual perceptions of the actors, based on the considered social factors, are determinant to define relations of hostilities. Relied on works from Huntington, Wendt, Castells, Waltz, Kissinger, among others, this work presents conceptual and theoretical foundations in order to understand this issue. We discuss the relationship of cultural factors in the new post-Cold War conflict dynamics, by arguing the emergence of the Islamic State and the

\footnotetext{
${ }^{1}$ Graduando em Relações Internacionais no Centro Universitário do Distrito Federal - UDF. Email: joaojp53@hotmail.com.

${ }^{2}$ Graduando em Relações Internacionais no Centro Universitário do Distrito Federal - UDF. Email: guilherme.adams@live.com.
} 
initiatives against Russian and European terrorists, and analysing how the specific cultural aspects of the actors relate to this.

Keywords: Clash of Civilizations; Terrorism; International Relations.

\section{Introdução}

O Terrorismo emerge no século XXI como uma das principais pautas de segurança internacional e continua aumentando o nível de preocupação de diversos Estados em relação a práticas brutais de violência que visam objetivos políticos ou religiosos. Concomitantemente, enquanto há a ascensão de uma ameaça que cada vez mais se coloca como uma forma de intimidação, diversos países seguem suas agendas políticas na tentativa de satisfazer seus respectivos interesses geopolíticos e de minimizar ameaças emergentes. Neste imbróglio, notam-se a influência de fatores culturais na constituição das dinâmicas de conflito características do período pós-guerra fria.

Este estudo é pautado em análises que partem do pressuposto da construção social da realidade e da influência de fatores culturais e identitários nos Estudos de Segurança Internacional. Como justificativa para a utilização de tal abordagem, percebe-se que questões históricas, culturais e identitárias influenciam a tomada de decisão dos atores envolvidos por meio da percepção de ameaças e da criação da imagem de inimigos.

Com este cenário, questiona-se aqui como as iniciativas contra terroristas europeias e russas podem ser percebidas em termos culturais que exercem influência nas relações internacionais? A hipótese levantada é que fatores sociais são determinantes na definição da atuação entre os atores pelo fato de as identidades permitirem fazer distinções entre "nós" e "eles", o que possibilita representações mútuas capazes de perceber ameaças e constituir inimigos. Por sua vez, isso pode determinar a utilização da violência. A fim de elucidar tal questão, o presente estudo possui como objetivo geral analisar a influência de fatores culturais nas dinâmicas de conflitos. Entre os objetivos específicos, estão, relacionar os fatores culturais com novas modalidades de conflito, verificar o surgimento do Estado Islâmico, identificar as iniciativas contra terroristas russas e europeias e analisar a influência de aspectos culturais e identitários na formulação de relações de hostilidade. Para atingir tais objetivos, foi realizada revisão da literatura, a fim de buscar uma base teórica condizente pertinente a temática. Especificamente, foram 
consultados livros, artigos, recortes de jornais e documentos oficiais disponibilizados pelos atores analisados.

\section{Choque de Civilizações e a Teoria Construtivista}

Como Samuel Huntington apresenta em sua obra, o mundo é geopoliticamente dividido em civilizações. De acordo com o autor "uma civilização é [...] o mais alto agrupamento cultural de pessoas e o mais amplo nível de identidade cultural que as pessoas têm aquém daquilo que distingue os seres humanos das demais espécies" (HUNTINGTON, 1996, p. 47-48). Ademais, é colocado que a divisão do mundo entre civilizações e identidades culturais, irão compor o (re)ordenamento da política mundial no período pós guerra fria, assim como os padrões de coesão, desintegração e conflito (HUNTINGTON, 1995, pg. 18-19).

As civilizações que interessam ao desenvolvimento deste trabalho são a Ocidental, a Ortodoxa e a Islâmica. Em relação a Ocidental, há vários Estados que a compõem, mas não definição se há um Estado-núcleo, isto é, líderes. A civilização Ocidental já teve vários Estados, mas poucos Estados-núcleos (HUNTINGTON, 1996, p. 50). Na civilização Ortodoxa, há um entendimento de a Rússia exercer o papel central, isto é, de Estado-núcleo. Por outro lado, sobre a civilização Islâmica, é interessante destacar que apesar de haver vários Estados, não há um que seja seu polo de poder, ou seja, não há um Estado-núcleo. Entretanto, a manifestação cultural religiosa desta civilização reflete na política de maneira que a ideia de soberania de um Estado-nação seja incompatível com a crença na soberania de Alá (HUNTINGTON, 1995, p. 219). Sobre isso, Huntington afirma que:

\footnotetext{
$\mathrm{Na}$ condição de movimento revolucionário, o fundamentalismo islâmico rejeita o Estado-nação em favor da unidade do Islã, exatamente do mesmo modo como o marxismo o rejeitava em favor da unidade do proletariado internacional (HUNTINGTON, 1995, p. 219).
}

Seguindo essa narrativa proposta por Huntington, outros autores possuem argumentos que a fortalecem. Como exemplo, Sayyid Qtub é tido como o escritor mais influente sobre o assunto do fundamentalismo islâmico (CASTELLS, 2018, p. 63), em que afirma que: 
Os laços de ideologia e fé são mais fortes que os laços de patriotismo fervoroso por uma região ou um território. Portanto, a falsa distinção entre muçulmanos baseada em territórios nada mais é que uma consequência das campanhas contra o Oriente, e do imperialismo sionista, que deve ser exterminada... a pátria não reside no território e sim no grupo de crentes da inteira uma islâmica (QTUB apud CASTELLS, 2018, p. 63).

Através desse ponto de vista islâmico de negação da autoridade soberana estatal como representante de sua civilização, tal agrupamento cultural possui diversos países e entidades subnacionais que atuam em seu nome - como é inclusive o caso da atuação do Daesh -, mas que não são aceitas por toda esta coletividade como seus representantes legítimos.

O reordenamento da política e da segurança internacionais através de linhas culturais e civilizacionais (HUNTINGTON, 1995, p. 153) somente são possíveis pela autoafirmação dos agentes em relação aos seus respectivos agrupamentos culturais, isto é, indivíduos estabelecidos dentro de uma civilização que se identificam com a cultura presente naquele local. Os indivíduos pertencentes a esses agrupamentos culturais são dotados de identidades. Em relação a este conceito, sua definição pode ser entendida conforme segue:

O processo de construção de significado com base em um atributo cultural, ou ainda, um conjunto de atributos culturais interrelacionados, o(s) qual(is) prevalece $(\mathrm{m})$ sobre outras fontes de significado (CASTELLS, 2018, p. 54).

De acordo com Bauman, "ter uma identidade parece ser uma das necessidades humanas mais universais" (BAUMAN, 2005, p. 46). O autor ainda afirma que:

A identidade 'pessoal' confere significado ao 'eu'. A identidade 'social' garante esse significado e, além disso, permite que se fale de um 'nós' em que o 'eu', precário e inseguro, possa se abrir, descansar em segurança e até se livrar de suas ansiedades (BAUMAN, 2005, p. 4647).

Outro argumento relevante sobre a questão da identidade, é a visão de que:

Embora, [...], as identidades também possam ser formadas a partir de instituições dominantes, somente assumem tal condição quando e se os atores sociais as internalizam, construindo seu significado com base nessa internalização (CASTELLS, 2018, p. 55). 
Huntington expressa que "as pessoas se congregam com as que têm semelhança de ascendência, religião, idioma, valores, e instituições, e se distanciam daquelas com diferenças nesses aspectos" (HUNTINGTON, 1996, p. 154) e que "num mundo muito fluido, as pessoas estão em busca de identidade e de segurança” (HUNTINGTON, 1996, p. 155). A formação dessas instituições citadas se realiza por meio de processos de formação de hábitos e "a institucionalização ocorre sempre que há uma tipificação recíproca de ações habituais por tipos de atores" (BERGER; LUCKMANN, 2014, p. 77). O compartilhamento de atributos culturais entre os indivíduos é considerado como pertencentes a identidades coletivas. Este termo é entendido conforme segue:

\footnotetext{
A identidade coletiva deriva do sentimento de que o grupo constitui uma entidade. No sistema internacional moderno, as identidades estão geralmente organizadas sob a forma de tribos, clãs, nações, civilizações e religiões (TANNO, 2003, p. 65).
}

Conforme o pensamento de que fatores culturais poderão exercer influência nas dinâmicas da política internacional, assim como em conflitos, tal composição se dá por meio da percepção de ameaças e construção de inimigos. Estes, por sua vez, se dão por meio de representações em que os atores as classificam conforme os significados que são específicos de suas interações. Por exemplo, "quinhentas armas nucleares Britânicas são menos ameaçadoras para os Estados Unidos do que cinco armas nucleares norte-coreanas por causa dos entendimentos compartilhados que as sustentam" (WENDT, 1999, p. 311). Em termos de capacidades materiais, os britânicos possuem maior potencial de ameaçar os Estados Unidos, mas na prática isso não ocorre simplesmente porque os norteamericanos não os consideram como inimigos. Entretanto, a mesma consideração que os Estados Unidos fazem em relação aos britânicos não é feita da mesma maneira em relação aos norte-coreanos. A forma pela qual os atores se representam mutuamente poderá determinar aqueles que são considerados como ameaças. Segundo Wendt, "o que dá sentido às forças de destruição são as 'relações de destruição' em que estão inseridas: são as ideias compartilhadas, sejam cooperativas ou conflituosas, que estruturam a violência entre os Estados" (WENDT, 1999, p. 311).

Nesse sentido, sobre a constituição de inimigos, a teoria Construtivista, ao abordar as possíveis posições de sujeito nas culturas da anarquia (amigo, rival e inimigo), afirma que "cada uma envolve uma postura distinta ou orientação do Self em relação ao Other no que diz respeito ao uso da violência [...]", e que "a postura de inimigos é aquela de 
adversários que ameaçam os que não observam os limites da violência entre si” (WENDT, 1999, p. 313). Ainda sobre a inimizade, são apontadas como características desta relação as representações do outro como um ator que não reconhece o direito de existência do Self e que não limitará a utilização da violência em relação ao Self (WENDT, 1999, p. 317). Em relação aos atores considerados aqui (União Europeia, Rússia e Daesh - talvez mais especificamente em relação ao Daesh), suas identidades se afirmam ao identificar inimigos e legitimar suas iniciativas em prol de suas lutas contra os "outros", dentra da lógica de "nós e eles" (HUNTINGTON, 1996, p. 159).

\title{
O reordenamento e a complexificação da segurança internacional e da geopolítica no pós- guerra fria
}

Há um consenso do atual período que compõe as Relações Internacionais contemporâneas tornou o sistema e a política internacionais mais complexas. Seguindo essa percepção, Huntington afirma que:

\begin{abstract}
A ilusão de harmonia no fim da Guerra Fria logo foi dissipada pela multiplicação de conflitos étnicos e de 'limpeza étnica', pela ruptura da lei e da ordem, pelo surgimento de novos padrões de alianças e conflitos entre os Estados, pelo ressurgimento de movimentos neocomunistas e neofascistas, pela intensificação do fundamentalismo religioso, pelo fim da 'diplomacia de sorrisos' e da 'política do sim' nas relações da Rússia com o Ocidente, pela incapacidade das Nações Unidas e dos Estados Unidos de acabarem com sangrentos conflitos locais e pela crescente disposição de afirmação de uma China emergente (HUNTINGTON, 1996, p. 32-33).
\end{abstract}

Ao contrário do que se afirma sobre o futuro não ser dedicado aos embates estimulantes sobre ideias e sim sobre a solução de problemas mundanos econômicos e técnicos (HUNTINGTON, 1996, p. 32), a realidade no sistema político internacional no imediato pós-guerra fria apresentou a emergência de conflitos gerados por grupo subnacionais, a fim de lutar para defender fatores que envolvem aspectos ideacionais. Como expõe Buzan e Hansen (2009) sobre a evolução da literatura dos Estudos de Segurança Internacional, e a importância dada à novos fatores que influenciam a temática:

Muito dessa literatura permaneceu dentro do enquadramento dominante de Segurança Internacional da Guerra Fria, mas uma parte dela começou a desafiar a ênfase nas capacidades materiais como no pressuposto estado-cêntrico, abrindo caminhos para estudos que 
privilegiassem ideias e culturas referentes à objetos de segurança para além do Estado (BUZAN e HANSEN, 2009).

É evidente a abrangência que tomou o sistema econômico capitalista liberal mundo afora, porém, os modelos político e ideológico ocidentais não foram amplamente aceitos e instaurados por todo o globo. Não obstante, nações e grupos subnacionais com interesses próprios, que certamente contrariam os interesses hegemônicos, surgiram dispostos a utilizar da violência para atingi-las. A partir disto, percebe-se o surgimento de novos coeficientes que são introduzidos como a reconfiguração da política mundial por meio de linhas culturais e civilizacionais (HUNTINGTON, 1996, p. 153), o que, novamente, apresenta dificuldade ao Ocidente de exercer seu pleno exercício de domínio sobre o sistema político mundial. Nesse sentido, Hawk, em sua análise sobre o Conceito da Política Externa russa de 2016, afirma que:

O Ocidente é também indiretamente responsável pela atual crise global devido a promoção de políticas econômicas neoliberais que apenas exacerbaram desigualdades desenvolvimentistas internacionais. Essas desigualdades significam que a luta por mercados e recursos apenas irão intensificar, a ponto de adquirir um caráter civilizatório (HAWK, 2017).

Por meio desta contextualização, o foco do presente estudo é tratar sobre questões que envolvem aspectos securitários. Sobre isto, o período inicial que compõe as relações internacionais contemporâneas foi marcado por diversos conflitos de natureza cultural, como disputas étnicas e religiosas. Como Huntington afirma: "O mundo ficou diferente no início dos anos 90, mas não necessariamente mais pacífico" (HUNTINGTON, 1996, p. 32).

Um dos aspectos relacionados à segurança e que será abordado aqui é a ascensão de práticas terroristas utilizadas por diversos grupos subnacionais. O terrorismo é introduzido neste debate, primeiramente, por sua falta de uma definição padrão e amplamente aceita. Como demonstração de tal complicação, o Governo norte-americano conceitua o termo como: "violência motivada politicamente premeditada contra alvos não-combatentes por grupos subnacionais ou agentes clandestinos, geralmente com intenção de influenciar uma audiência" (US DEPARTMENT OF STATE apud ROGERS, 2008, p. 174), enquanto que outra definição, mais completa, seria: 
Uso, ou ameaça do uso, da violência por um indivíduo ou um grupo, seja atuando para ou em oposição à uma autoridade estabelecida, quando tal ação é designada como criadora de extrema ansiedade e/ou medo em um grupo maior do que as vítimas imediatas com o propósito de coagir esse grupo a aceder às demandas políticas do perpetrador (WARDLAW apud ROGERS, 2008).

Por meio das definições expostas pode-se concluir, através da extração de pontos em comum das diferentes citações, que o terrorismo consiste no uso da violência, ou da ameaça de uso desta, para propagar o medo a um público maior do que o alvo de seus atentados, com o fim de serem atingidos interesses de cunho político.

\section{A ascensão do Terrorismo e o surgimento do Estado Islâmico}

Desde os ataques de 11 setembro de 2001, o terrorismo alcançou um lugar especial na pauta de segurança internacional. Em decorrência disso, em 2002 e 2003, a "Doutrina Bush" e a declaração de "Guerra ao Terror", foram responsáveis pela "visita" das Forças Armadas norte-americanas ao Oriente-médio mais uma vez, especificamente, ao Afeganistão e ao Iraque. A deflagração da guerra no Iraque e seus desdobramentos tiveram grandes consequências e repercussões. Dentro deste contexto, a guerra desestabilizou o Iraque e permitiu o surgimento e ascensão de diversos grupos fundamentalistas que, frequentemente, recorriam à violência para resolver problemas e atingir seus objetivos. Dentre estes grupos, surgiu aquele que posteriormente proclamou um Califado e se auto denominou o "Estado Islâmico do Iraque e do Levante", da tradução em árabe al-Daula al-Islamiya al-Iraq wa Sham (Daesh). É fato que a intervenção militar norte-americana, por si só, não foi o único fator causador do surgimento de um grupo tão radicalizado como o Daesh. Outra causa para a extraordinária expansão do grupo terrorista foi a vantagem tirada do grupo de um "vácuo de poder" ocasionado pela deflagração de guerras civis em alguns países, suscitado pela Primavera Árabe, em especial, a guerra civil na Síria. Segundo Napoleoni:

[...] o conflito na Síria proporcionou uma oportunidade única, uma plataforma de lançamento, para os que haviam assimilado a mensagem de al-Zarqawi e que desejavam concretizar o sonho dele, entre os quais Abu Bakr al-Baghdadi, o novo Califa (NAPOLEONI, 2015).

O início da guerra civil na Síria, em 2011, em decorrência da famigerada Primavera Árabe, abriu caminho para o grupo terrorista que vinha se fortalecendo. O 
Estado Islâmico se originou através da herança da visão de mundo extremada de um jordaniano que após ser preso, abraçou o salafismo radical (NAPOLEONI, 2015), Abu Musab al-Zarqawi. Este foi reconhecido por Osama bin Laden como o chefe da Al-Qaeda no Iraque entre 2003 e 2004 (NAPOLEONI, 2015), e, após dois anos de intensa dedicação à organização terrorista, por meio da promoção de diversos atentados suicidas, foi morto em um ataque aéreo norte-americano (NAPOLEONI, 2015). A partir da liderança exercida por Abu Bakr al-Baghdadi em 2010, o novo chefe da ala da al-Qaeda, e com grandes ambições, percebeu no recém iniciado conflito sírio, era uma oportunidade de crescimento militar da organização (NAPOLEONI, 2015). A descoberta de al-Baghdadi foi que:

[...] a guerra por procuração na Síria serviu não apenas para fornecer aos membros do EI treinamento militar, mas proporcionou também os recursos financeiros para a remodelação do grupo, transformando-o não apenas em mais uma das muitas organizações jihadistas armadas, mas num participante de importância fundamental no jogo dos conflitos regionais, com sua própria fortaleza territorial e máquina militar (NAPOLEONI, 2015).

Umas das ideias do Daesh, criada por al-Zarqawi, defendida e levada a cabo por al-Baghdadi, foi a conquista e incorporação de territórios a serem controlados pelo grupo terrorista. A lógica da atuação pretendida pelos terroristas era "[...] uma guerra de conquistas de porta em porta, ocupando cidades e impondo a xariá em todas elas" (NAPOLEONI, 2015). Novamente, segundo Napoleoni:

Pela primeira vez na história moderna, uma organização armada terá alcançado o objetivo final do terrorismo: criar seu próprio Estado nacional com as cinzas de nações consolidadas, e não por meio de uma revolução, tal como aconteceu no Irã, mas com uma guerra de conquista tradicional com base em táticas terroristas (NAPOLEONI, 2015).

A autora conclui a argumentação em relação à proposta de atuação do Daesh, afirmando que se tal fato se consolidasse, o grupo se tornaria um novo modelo do terrorismo a ser seguido. Portanto, pode-se perceber uma evolução da atuação terrorista islâmica, baseada em visões extremadas que serviram como uma herança que foi seguida por aqueles que com ela simpatizavam. A atuação da al-Qaeda, ao demonstrar sua capacidade e poder alçando um feito inédito, o ataque à Torres Gêmeas (única vez em que os Estados Unidos foram atacados em seu próprio território), foi algo que dificilmente seria superado, entretanto, ao que aparenta, Abu Bakr al-Baghdadi, influenciado 
fortemente pelas crenças de al-Zarqawi, superou Osama bin Laden, apresentando uma nova forma de atuação do terrorismo jamais vista na história.

Além das grandes conquistas territoriais, o Daesh conseguiu projetar seu poder pelo mundo ao promover vários atentados na Europa. Os países europeus, em sua maioria sob a égide da União Europeia, já se preocupavam com o terror e foram obrigados a fazêlo de maneira ainda mais intensa, buscando a consolidação de sua segurança. A Rússia também foi alvo de atentados, o que a colocou como um ator que necessitou aderir ao combate ao terror, entretanto, sua relação não se deu da mesma forma como no caso da Europa, havendo especificidades da história da atuação terrorista em relação à ambos.

\section{União Europeia e Rússia no combate ao Estado Islâmico}

A atuação deste grupo terrorista alçou maior visibilidade com os diversos atentados e suas ações cruéis em seu próprio território. Para combater estas práticas, que representam ameaça à segurança, não somente dos cidadãos, mas que, em última instância, objetivam a destruição do sistema civilizacional ocidental vigente e sua respectiva substituição pela normatividade imposta pela Sharia, a União Europeia e a Rússia dispuseram de diversas iniciativas no plano operacional a fim de promover resistência frente à ameaça terrorista.

De acordo com Paul Rogers (2008), há três formas de responder ao terrorismo. Estas são: iniciativas pautadas principalmente no policiamento, inteligência e segurança; abordagens baseadas no envolvimento militar; e abordagens que tem por finalidade desmantelar as motivações implícitas dos terroristas, assim como o ambiente pelo qual estes adquirem apoio (WILLIAMS et al, 2008, p. 175). Ainda segundo o autor, a maioria das ações de contraterrorismo ocorrem de forma a combinar esses diferentes tipos de abordagem, entretanto, não há uma regra quanto à isso, e o meio pelo qual será empregada a resposta ao terror, pode variar.

A partir deste ponto, serão identificadas e analisadas as iniciativas de contraterrorismo propostas e praticadas pela UE e Rússia, com o objetivo de desmantelar o Daesh, considerando possíveis interesses paralelos destes atores em relação às disputas geopolíticas. 


\section{O contraterrorismo europeu}

As ações contra terroristas praticadas pela União Europeia se encontram presentes em documentos oficiais disponibilizados pelo organismo supranacional. Estas se baseiam em 4 pilares: Prevenção, Proteção, Perseguição e Resposta. Em suma, estes pontos basilares possuem o objetivo de 1) evitar a radicalização e outras possíveis causas que podem levar a atentados; 2) diminuir a vulnerabilidade de alvos sensíveis (infraestrutura, transportes e instalações governamentais); 3) diminuir a capacidade de articulação de organizações terroristas impedindo seu financiamento e comunicação - reforçando as capacidades individuais de cada estado-membro, assim como a cooperação entre estes; e 4) se preparando para agir da melhor forma possível na ocorrência de outro possível atentado.

Além destas iniciativas, há outras, mais específicas, que auxiliam no combate ao terrorismo. Com o aumento da insegurança frente a ameaça do terror, a UE promoveu mudanças no que se refere à obtenção de armas de fogo, alterando a legislação e tornando mais difícil a obtenção de armas, assim como proibindo a utilização de alguns tipos de armamento pela população civil - ao considerar que em alguns casos os terroristas as adquiriram de forma legítima. Também foram colocadas em prática leis que punem quem tentar se juntar a algum grupo terrorista, criminalizam viagens ao exterior da comunidade para objetivos terroristas, assim como ações que facilitem tais movimentações e fornecer ou receber treinamento ou meios de financiamento para tais práticas. Além disso, o reforço na segurança das fronteiras externas da comunidade europeia também foi alvo de preocupação. Outra alteração na legislação permitiu o controle de entrada e saída de todos por meio de uma análise em um banco de dados que contém informações que podem auxiliar na identificação de algum suspeito.

Tais providências tomadas pela União Europeia se justificam com a elevada quantidade de imigrantes e refugiados que têm entrado na região, decorrentes das guerras ocorrentes no Oriente-Médio, em especial a guerra-civil síria. O agravante da presença do Daesh na guerra-civil tornou a situação cada vez pior, contribuindo ainda mais para o número de pessoas deslocadas por causa do conflito. O grande fluxo de imigrantes pressionou a UE, ao considerar que a opinião de como a comunidade deveria tratar a situação foi dividida, havendo países que defendem o fechamento de suas fronteiras e outros optando por receber os imigrantes. Entretanto, não somente imigrantes geram desconfiança, mas a própria população europeia que segue a religião islâmica. Tal ideia 
pode ser percebida de acordo com Paul R. Pillar, que afirma que "por inúmeros governos, atenção às raízes do terrorismo tem mais relação com as suas respectivas populações muçulmanas" (WILLIAMS et al, 2008, p. 377). Essa atenção se justifica ao considerar o crescimento da população muçulmana na Europa, onde há estimativas de que ela pode aumentar consideravelmente, mesmo que não haja imigração de países com maioria muçulmana, e a efetiva participação de europeus no conflito da Síria ao lado do Daesh. A respeito desta presença de cidadãos europeus compondo as fileiras do grupo terrorista, dados do Global Terrorism Index de 2017 mostram que, em 2016, era estimado que houvessem entre 3.900 a 4.900 combatentes estrangeiros, e que a maioria destes provinham da Bélgica, França Alemanha e Reino Unido.

As iniciativas praticadas pela União Europeia tiveram o objetivo de proteger a comunidade internamente, entretanto, tal feito também foi realizado com a criação de uma coalizão lideradas pelos EUA e com a participação de membros da OTAN. No entanto, esta intervenção no conflito sírio é contestada, sobretudo, pelos interesses paralelos que estes atores possuem em relação à Síria, havendo oportunidade de atingir tais interesses, econômicos e estratégicos se aproveitando da situação de caos em que o país árabe se encontra. Bandeira trata sobre tal questão e afirma que:

\footnotetext{
Em 4 de abril de 2011, quando as manifestações contra o regime de Bashar al-Assad se intensificaram, os Estados Unidos, França e GrãBretanha, com o apoio da Alemanha e Portugal, tentaram repetir contra a Síria no Conselho de Segurança da ONU a mesma tramoia, que haviam armado contra o regime de Gaddafi (BANDEIRA, 2016, p. 178).
}

Na ocasião, foi utilizado como argumento a Responsabilidade de Proteger (R2P) contra o Presidente sírio, alegando mortes de manifestantes devido à forte repressão do regime. Contudo, Rússia e China, com o apoio de Brasil, Índia e África do Sul, vetaram a proposta (BANDEIRA, 2016, p. 178).

A atuação contra terrorista europeia é pautada em iniciativas que podem ser entendidas como duas grandes vertentes: as ações para o fortalecimento de suas capacidades domésticas para lidar com o terrorismo e a suas iniciativas externas focadas no combate direto nos países originários dos grupos percebidos como ameaças. Neste primeiro, pode-se inferir que, das formas de contraterrorismo, a forma presente no ambiente doméstico europeu é voltada para o policiamento e a segurança de forma geral, e encontra diversos problemas ao se levar em conta a crescente presença de imigrantes e 
de cidadãos europeus muçulmanos e a grande dificuldade, senão a incapacidade, da Europa de promover sua segurança. Conforme Paul R. Pillar manifesta:

\begin{abstract}
As circunstâncias geográficas e outras de cada país, no entanto, tornam a segurança nacional diferente para cada um. Para a maioria dos países europeus, o movimento transfronteiriço aberto dentro da União Europeia tornaria impossível para Estados individuais em abordar a própria segurança nacional como os Estados Unidos (WILLIAMS et al, 2008, p. 381).
\end{abstract}

Contudo, a maneira pela qual a Europa age fora de seu próprio território é mais voltado para iniciativas militares. Desde de meados 2014, a OTAN formalizou sua participação na coalizão formada para realizar operações militares contra as posições do grupo terrorista na Síria, estabilizar as regiões liberadas do domínio terrorista e o fortalecimento da cooperação internacional para acabar com o financiamento, o recrutamento e a neutralização do discurso extremista do Daesh.

\title{
O Contraterrorismo Russo
}

A Rússia, ao contrário da União Europeia, age de forma mais direta no conflito, não somente participando de coalizões, mas intervindo diretamente na situação. A intervenção na guerra civil-síria foi realizada com aval do governo sírio, liderado por Bashar Hafez al-Assad devido à uma histórica aliança entre os dois países. Vale apontar que o combate da Rússia ao terrorismo se mistura com uma questão particular histórica russa, a guerra da Chechênia. A região separatista russa, no norte do Cáucaso, é o local onde há o maior número de muçulmanos na Rússia. A partir da queda da União Soviética e o movimento de diversas repúblicas soviéticas na direção da independência, a pequena região também ousou adquirir o status de Estado independente, mais especificamente, um Estado Islâmico. A situação se complica mais ao misturar o modus operandi dos chechenos entre o terrorismo e a insurgência (CLARKE, 2017). A insurgência, conforme definida pela doutrina militar britânica se refere a "um movimento organizado que visa atacar o governo constituído com o uso de subversão e conflito armado" (UK Ministry of Defense apud SPEAR, 2008, p. 392). A autora Joanna Spears aborda sobre a questão da insurgência, afirmando que: "é um truísmo que uma contrainsurgência efetiva envolve ganhar 'corações e mentes' da população local” (WILLIAMS et al, 2008, p. 397). Seguindo essa linha de pensamento, Huntington afirma sobre a guerra ocasionada pela tentativa de separatismo da Chechênia que: 
Nos anos 90, Dudayev capitalizou sobre o Ressurgimento Islâmico que tinha ocorrido no Cáucaso na década de 80 [...]. Ele recebeu o apoio de sacerdotes muçulmanos e de partidos fundamentalistas islâmicos, fez seu juramento de posse sobre o Corão (do mesmo modo que Yeltsin fez sobre a Bíblia) e, em 1994, propôs que a Chechênia se tornasse um Estado islâmico governado segundo a Shari'a. As tropas chechenas usavam lenços verdes, 'inscritos com a palavra 'Gavazaf, que quer dizer guerra santa em checheno', e gritavam 'Allahu Akbar' quando se lançavam ao combate (HUNTINGTON, 1996, p. 341).

Com a ascensão do terrorismo na Síria, através da atuação do Estado Islâmico, vários destes russos que compartilhavam da visão de que seria necessário um califado para impor as leis islâmicas, se juntaram ao grupo terrorista, fortalecendo o terror na região. Segundo estatísticas, o idioma russo era o terceiro mais falado e a nacionalidade russa era a terceira maior dentro do Daesh (Global Terrorism Index, 2017, p. 67). Nesse sentido, conforme é exposto no Global Terrorism Index de 2017:

\footnotetext{
Em 2015, indivíduos com nacionalidade russa compunham cerca de $8 \%$ dos soldados do Estado Islâmico. O grupo terrorista tem feito esforços substanciais para alcançar a audiência de língua russa via mídia social e propagandas. O russo é a terceira língua mais utilizada pelo grupo, depois do Árabe e Inglês (GLOBAL TERRORISM INDEX, 2017, p. 67-68)
}

Tal fato demonstra a ameaça representada para o maior país do mundo. Mais recentemente, em 2016, a Rússia lançou seu novo Conceito de Política Externa, documento onde são apresentadas metas sobre suas relações internacionais. Neste, há menção ao terrorismo, expressando que tal ameaça "[...] havia alcançado um novo patamar com a emergência do Estado Islamico como uma organização terrorista internacional e grupos similares que usam um nível improcedente de crueldade na forma de empregar violência” (Foreign Policy Concept of the Russian Federation, § 15), e classifica as formas de combate ao terrorismo como "objetivo essencial do governo e um elemento chave para a segurança internacional" (Foreign Policy Concept of the Russian Federation, § 33).

A ascensão do terrorismo no Oriente-Médio representa ameaça direta à Rússia, considerando seus movimentos separatistas e terroristas na região próxima, o Cáucaso. Logo, a desestabilização da região vizinha poderia causar efeitos diretos em seu próprio 
território. Ainda, há a disputa geopolítica com outros países e a decisão russa de participar ativamente do conflito na Síria pode ser vista como uma forma de confrontar os interesses das potências norte-americana e europeias e de exercer maior controle e influência em uma área também de seu interesse. Abordando essa questão de disputa de interesses, Bandeira expõe que houve tentativas fazer com que a Rússia retirasse o apoio a Assad, oferecendo alguns benefícios se o governo russo não barrasse uma resolução no Conselho de Segurança da ONU que permitisse uma intervenção no país (BANDEIRA, 2016, p. 181).

Portanto, sobre a intervenção russa na Síria, percebe-se que a atuação da política externa da Rússia neste ponto se mistura na tentativa de confrontar os interesses norteamericanos e europeus na região, de resolver um grave problema interno de segurança que ameaça sua integridade territorial e exercer maior influência em seu entorno estratégico. O terrorismo no Cáucaso apenas cresceu no início do século, representando ainda mais ameaça ao país, e o surgimento de novas dinâmicas influenciam e ameaçam desestabilizar a região. Por esse ângulo, Hawk expressa que o poder cada vez menos presente do Ocidente, e o vácuo de poder gerado, representam um problema ao sistema internacional ao possibilitar que essa ausência de poder seja preenchida por grupos extremistas que configuram ameaça de primeira ordem, como o Daesh.

A atuação da Rússia no combate ao terror não é nova, e a presença de seus próprios cidadãos no principal grupo terrorista da atualidade demonstra uma "extensão" de um problema doméstico que, sob a forte influência de aspectos culturais, se tornou um fator agravante que ameaça a segurança internacional. Como exposto na Doutrina de Informação de Segurança da Rússia (2016), vários grupos terroristas utilizam de uma crescente onda de informações como ferramenta para influenciar indivíduos, grupos e a consciência pública com o objetivo de explorar tensões sociais e étnicas e incitar o ódio e hostilidade entre grupos étnicos e religiosos. Essas tensões podem ser identificadas ao se considerar que a Rússia é um país dividido, havendo em sua maioria uma população identificada com a religião ortodoxa, e no norte do Cáucaso, uma maioria muçulmana.

\section{União Europeia e Rússia no combate ao Estado Islâmico como choque de civilizações}

Se faz presente aqui o argumento de que diferenças culturais são realmente fatores que exercem influência na deflagração de conflitos entre atores de agrupamentos distintos. Waltz, por outro lado, aborda a ideia de promoção da compreensão internacional 
como forma de promoção da paz (WALTZ, 2004, p. 62). Seguindo esse raciocínio, ele questiona: "mas como essas incompreensões levam a guerra (entre Estados)?” (WALTZ, 2004, p. 62) e “inversamente, será que a compreensão sempre promove a paz precisamente porque não compreendem muito bem umas às outras?" (WALTZ, 2004, p. 62). Não obstante, ele afirma ainda que, talvez essa hipótese de promover a compreensão entre os agrupamentos culturais com visões distintas da realidade não seja uma solução definitiva (WALTZ, 2004, p. 64). Nesse sentido, argumenta que "uma grande afinidade cultural não tem reduzido o derramamento de sangue, como ilustra amplamente a história da Europa Ocidental" (WALTZ, 2004, p. 64) e utiliza uma citação de Karl Deutsch, em que afirma:

\footnotetext{
Muitos indivíduos emocional, cultural e politicamente sensíveis reagem a uma temporada no exterior... com uma formação bem mais forte do nacionalismo e da lealdade à sua própria língua, à sua própria cultura e ao seu próprio povo (DEUTSCH apud WALTZ, 2004, p. 64).
}

Contudo, a ideia de autoafirmação dos grupos em relação às suas identidades seja se tratando de fortalecimento do sentimento nacionalista ou religioso -, se encontra como um impedimento à hipótese proposta por Waltz, com a possibilidade de que a compreensão entre grupos conflitantes não acarrete no desencadeamento da paz, mas na deflagração da ocorrência da violência.

Outra contribuição significativa presente em "O Homem, o Estado e a Guerra" é a proposta de que a guerra se trata de uma instituição social e "não um produto necessário da natureza humana" (WALTZ, 2004, p. 65-66), e que "o conhecimento obtido por meio do estudo de outras culturas deve ser usado para aprimorar as várias sociedades" (WALTZ, 2004, p. 65), com o objetivo de fazer com que ela deixe tal condição de instituição socialmente aceita. Como evidência disso, é exposto o fato de a guerra não existir em algumas sociedades (WALTZ, 2004, p. 66), ou como no caso das civilizações estudadas neste trabalho, o fato dela se fazer mais presente em umas do que em outras. $\mathrm{O}$ Ocidente, em particular a Europa, possui um longo e conhecido histórico da ocorrência de guerras, assim como a Rússia. No caso da civilização islâmica, essa realidade é mais óbvia e se faz mais presente na história recente ao se considerar que, nas chamadas guerras de linhas de fratura (HUNTINGTON, 1995, p. 320), o Islã se destaca como o agrupamento que mais recorre à utilização da violência para solucionar as animosidades que a circundam. 
Logo, a ideia da construção de uma identidade coletiva se faz presente nesta análise ao perceber que as diferentes civilizações aqui consideradas possuem distintas visões acerca de seus respectivos modelos ideais para a organização do mundo. Civilização e cultura "envolvem 'os valores, as normas, as instituições e os modos de pensar aos quais sucessivas gerações numa determinada sociedade atribuíram uma importância fundamental” (BOZEMAN apud HUNTINGTON, 1996, p. 46). Pode-se ainda considerar que a raiz dos conflitos baseadas em ideias podem se iniciar nas percepções de ameaças destas, ou seja, ao identificar valores que definem as respectivas formas de condução de uma sociedade como potenciais ameaças à sobrevivência de ideias valorizadas por outra, e que sem a garantia de que tais fatores dotados de significação poderão sobreviver, tampouco poderá o grupo. Sobre isso, de acordo com Calhoun (1994), "não temos conhecimento de um povo que não tenha nomes, idiomas ou culturas em que alguma forma de distinção entre o eu e o outro, nós e eles, não seja estabelecida..." (CALHOUN apud CASTELLS, 2018, p. 54). Essa percepção e distinção entre "nós e eles" também se faz presente nas argumentações de Huntington:

\footnotetext{
Uma Weltanshauung sinistra dessa nova era foi muito bem expressada pelo demagogo nacionalista veneziano no romance de Michael Dibdin, Dean Lagoon: 'Não é possível haver amigos verdadeiros sem inimigos verdadeiros. A menos que odiemos o que não somos, não podemos amar o que somos... (HUNTINGTON, 1996, p. 18).
}

Isso pode ser percebido também com base na ideia da organização da sociedade por meio dos valores cultuados por cada agrupamento cultural, conforme Kissinger manifesta em relação ao Islã:

\footnotetext{
As áreas conquistadas pelo Islã ou aquelas nas quais exercia seu domínio sobre povos não muçulmanos que pagavam tributos eram concebidos como uma única unidade política: das al-Islam, a 'Casa do Islã', ou o domínio da paz. Este seria governado por um Califado, uma instituição definida pela sucessão ordeira da autoridade política terrena que o Profeta havia exercido. As terras para além dessa área eram a das al-harb, o domínio da guerra; a missão do Islã era incorporar essas regiões ao seu próprio mundo, promovendo, assim, a paz mundial (KISSINGER, 2015).
}

Em sequência, Kissinger utiliza uma citação Majid Khadduri, onde ele manifesta que: 
O dar al-Islam, em teoria, estava em estado de guerra com o dar al-harb, porque o objetivo supremo do Islã era o mundo inteiro. Se o dar al-harb fosse reduzido pelo Islã, a ordem pública da Pax Islamica seria superada pelas outras, as comunidades não muçulmanas iriam ou se tornar parte da comunidade islâmica ou se submeter à sua soberania na condição de comunidades religiosas toleradas ou como entidades autônomas com as quais se relacionariam por meio de tratados (KHADDURI apud KISSINGER, 2015).

Kissinger argumenta, ainda, que a jihad é uma estratégia voltada para a construção deste sistema universal islâmico e que esta se trata de "um dever obrigatório para os crentes no sentido de expandir sua fé por meio da luta" (KISSINGER, 2015). Entretanto, ele afirma que o meio pelo qual se dá a forma de organização e condução do mundo pelo Islamismo, a jihad, abrange a guerra, mas não se resume exclusivamente à uma estratégia militar (KISSINGER, 2015). Nesse sentido, ele conclui a argumentação recorrendo à outra citação de Khadduri, em que diz que "o crente poderia cumprir o dever do jihad, com o seu coração, com a sua língua, com as suas mãos, ou pela espada" (KHADDURI apud KISSINGER, 2015).

Dito isso, a percepção de ameaça e a criação da imagem de um inimigo entre os atores analisados no presente trabalho, pode ser compreendida, inicialmente, através da atuação da Al-Qaeda e dos Estados Unidos no contexto de conflitos do Oriente-Médio, levando em consideração que o Daesh se originou dentro do grupo terrorista liderado por Osama Bin Laden. Posteriormente, a destacada atuação de Abu Musab al-Zarqawi, teve, na prática, a finalidade de levar a cabo, e além, a já radicalizada visão de mundo de Bin Laden. Como Castells destaca:

\footnotetext{
O movimento simbolicamente representado pela Al-Qaeda, [...], é um tipo diferente de movimento. De fato, ele é baseado no fundamentalismo islâmico, mas é explicitamente global na definição de seu adversário, em seu suporte e em suas Táticas. Ele é construído pela definição do adversário, não numa definição de seu princípio identitário (CASTELLS, 2018, p. 160-161).
}

O autor se refere à principal organização terrorista antecessora do Daesh como um tipo diferente ou especial de movimento social, e a compreende como uma "ação coletiva propositada visando à modificação dos valores dominantes e das instituições da sociedade em nome dos valores e interesses que são relevantes para os atores do 
movimento" (CASTELLS, 2018, p. 161). Neste momento, Huntington retorna ao debate somando seus argumentos ao de Castells, quando afirma sobre o aumento da consciência civilizacional:

\begin{abstract}
À medida que a violência aumenta, as questões que estavam inicialmente em pauta tendem a ser redefinidas de modo mais exclusivo como 'nós' contra 'eles', e aumentam a coesão e dedicação do grupo. Os líderes políticos ampliam e aprofundam seus apelos a lealdades étnicas e religiosas, e a consciência da civilização se reforça em relação a outras identidades. Surge uma 'dinâmica de ódio', comparável ao 'dilema de segurança' nas relações internacionais, na qual os temores, a desconfiança e o ódio recíprocos se alimentam mutuamente (HUNTINGTON, 1996, p. 338).
\end{abstract}

Em complementação, Castells afirma que "todos são inspirados por um ódio comum ao adversário e por uma crença comum no bem do martírio em nome do islã" (CASTELLS, 2018, p. 161). Uma argumentação de Huntington fortalece a ideia de definição e motivação das atuações violentas de determinados atores movidos por meio de percepções de uma ameaça e construção de um inimigo, afirmando que "no curso da guerra, as identidades múltiplas se desvanecem e a identidade mais relevante em relação ao conflito passa a predominar" (HUNTINGTON, 1996, p. 340). Ainda segundo o autor, a religião exerce grande papel na definição de tais identidades. Portanto, fica evidente a ideia da criação de uma identidade coletiva em torno da percepção de ameaças a valores caros, considerados de extrema importância para a condução de suas respectivas sociedades e que constitui uma ameaça existencial à sobrevivência do "nós" (ESCORREGA, 2014). Logo, a disputa entre os atores se dá para definir qual será a melhor forma de organização e condução da sociedade, e, do ponto de vista do terrorismo islâmico, a interpretação do islã realizada pelos líderes terroristas é que este é visto "como o único guia para o comportamento do povo e da sociedade" (CASTELLS, 2018, p. 162).

Em relação ao aumento do ódio e do fortalecimento do sentimento de identidade a determinado grupo, Castells ainda propõe a ideia que "o ataque contra os cruzados continua, a fim de libertar as terras muçulmanas dos infiéis, sejam eles sovietes no Afeganistão, americanos na Arábia Saudita ou, finalmente, judeus na Palestina" (CASTELLS, 2018, p. 161). Desta forma, se faz evidente a ideia de que quaisquer atores que representem ameaça àquilo que é considerado de extremo valor para determinado agrupamento cultural, podem ser vistos como inimigos em potencial. Por outro lado, as 
ações terroristas praticadas com o objetivo final de derrotar seus inimigos em suas próprias terras e impor suas visões e seu modo de vida para as demais sociedades são percebidas como ameaça pelas outras civilizações (Ocidental e Ortodoxa) pelo constante uso da violência, característico de seu modus operandi. Isso faz com que, após uma ameaça ser identificada, quem a propaga se torne um inimigo.

Como o terror atua em diversas frentes, ou seja, contra vários países, isto possibilita que aqueles ameaçados pelo temor de serem atacados de surpresa se unam e operem em conjunto a fim de combater um inimigo em comum. Por outro lado, as ações antiterroristas adotadas por esses outros países, ameaçados pelo terror, reafirmam a ideia bastante presente no debate, do "nós contra eles", alimentando o ódio e fortalecendo seus sentimentos de autoafirmação identitária em relação a um grupo, comunidade, agrupamento cultural, civilização... As iniciativas empregadas pelos europeus e pelos russos em suas guerras contra o terror na Síria, ainda que em situação de legítima defesa em resposta a atentados, ou simplesmente na busca por seus interesses - ou ambos acabam por legitimar o discurso propagado pelos líderes terroristas, que solidificam suas retóricas e conquistam mais adeptos com a definição de alguém assumindo o papel de inimigo de toda uma coletividade. A possibilidade de conflitos entre os atores analisados é colocada por Huntington como conflitos de linhas de fratura. Citando o autor:

Ocorrem os conflitos de linha de fratura entre Estados vizinhos de civilizações diferentes, entre grupos de civilizações diferentes no mesmo Estado e entre grupos que estão tentando criar novos Estados com os destroços do Estado antigo.(HUNTINGTON, 1996, p. 206).

A principal localização do grupo terrorista foi na Síria, em meio à guerra-civil que os extremistas conseguiram tirar proveito para maximizar seus ganhos territoriais, assim como o principal local de atuação contraterrorismo europeia e russa. A situação percebida na Síria se encaixa nas duas últimas possibilidades de ocorrência de conflitos de linha de fratura expostos por Huntington, pela presença de grupos de origens culturais distintas combatendo em um mesmo local e pela atuação fracassada do Daesh de tentar erguer um Estado islâmico em meio ao caos ocasionado pela guerra-civil que enfraqueceu o regime de Assad. 


\section{Conclusão}

Com base no que foi exposto, se considera aqui, que as civilizações Ocidental, Ortodoxa e Islâmica, configuram conflitos intercivilizacionais. Isso acontece, inicialmente, por meio das iniciativas contra terroristas russas e europeias e suas atuações em participações de outras guerras no Oriente-Médio contra a "coletividade muçulmana" de forma geral, contudo, isto se dá pela fato destes agrupamentos culturais possuírem formas tão distintas de organização de suas realidades que estão dispostos à utilização da violência, isto é, da guerra como meio para resolver seus problemas e para concretizar seus ideais e a sua supremacia de seus valores e de sua cultura sobre as demais. A ideia de agrupamentos culturais com identidades coletivas, que as baseiam na valorização de seus valores e significados, se faz presente ao levar em consideração que mesmo quando grupos culturais distintos convivem em um mesmo ambiente a divisão entre estes não desaparece. Como exemplo disto, pode-se considerar a crescente sentimento de xenofobia na Europa, até mesmo em relação àqueles que nasceram naquela região, mas que proferem uma religião diferente da cristã - característica da civilização Ocidental. Não somente a identidade coletiva se reafirma em torno dos valores e significados em comum cultuados por uma coletividade, mas também relação à percepção de ameaças e da identificação de inimigos. Dentro da lógica do "nós contra eles", a autoafirmação identitária, por vezes, é mais expressiva ao se tratar do fortalecimento de tal sentimento em torno de criação da imagem de inimigos, abrindo espaço para uma "identidade mais relevante em relação ao conflito", que pode se tornar predominante.

Contudo, considera-se também que as disputas travadas entre essas civilizações não se dão somente em termos imediatos, no sentido de simples resposta a ataques perpetuados pelo outro lado, mas disputas de ideias sobre o futuro da organização e condução de suas sociedades, com cada um destes lutando por poder e orientados pela identidade coletiva do conflito baseada na percepção de inimigos. Portanto, as iniciativas da União Europeia e Rússia no combate ao Estado Islâmico se misturam com fatores históricos de conflitos entre grupos com matrizes culturais diferentes e a internalização da identidade do conflito como consequência disso, além dessas ações se confundirem com questões domésticas e externas, demonstrando a complexidade dessas relações. 


\section{Referências bibliográficas}

BANDEIRA, L. A. M. A Desordem Mundial: O Espectro da Total Dominação: Guerras por Procuração, Terror, Caos e Catástrofes Humanitárias. Rio de Janeiro: Editora Civilização Brasileira, 2016.

BAUMAN, Z. Medo Líquido. Rio de Janeiro: Zahar, 2008.

_.. Ensaios sobre o Conceito de Cultura. Rio de Janeiro: Zahar, 2005.

BERGER, P.; LUCKMANN, T. A Construção Social da Realidade. Editora Vozes, 2014.

BUZAN, B.; HANSEN, L. The Evolution of International Security Studies. New York: Cambridge University Press, 2009.

CASTELlS, M. O Poder da Identidade: A Era da Informação. São Paulo/Rio de Janeiro: Paz e Terra, 2018.

CLARKE, C. P. Jihadist Violence on the Caucasus: Russia Between Counterterrorism and Counterinsurgency. Rand Corporation, 2017. Disponível em: <https://www.rand.org/content/dam/rand/pubs/testimonies/CT400/CT483/RAND_CT48 3.pdf> Data de acesso: 25 ago. 2018.

ESCORREGA, L. C. F. A Segurança e os "Novos" Riscos e Ameaças: Perspectivas Várias. Revista Militar, 2014. Disponível em: <https://www.revistamilitar.pt/revista/2491> Data de acesso: 20 out. 2018.

CONSELHO EUROPEU. União Europeia. Estratégia Antiterrorista da EU, Disponível em: <https://www.consilium.europa.eu/pt/policies/fight-against-terrorism/eu-strategy/> Data de acesso: 20 out. 2018.

FEDERAÇÃO RUSSA. Foreign Policy Concept of the Russian Federation. 2016a. Disponível em: <http://www.mid.ru/en/foreign_policy/official_documents//asset_publisher/CptICkB6BZ29/content/id/2542248?p_p_id=101_INSTANCE_CptICk B6BZ29\&_101_INSTANCE_CptICkB6BZ29_languageId=en_GB $>$. Data de acesso: 15 set. 2018.

_. Doctrine of Information Security of the Russian Federation. 2016b Disponível

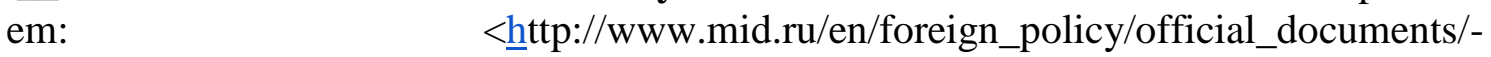
/asset_publisher/CptICkB6BZ29/content/id/2563163>. Data de acesso: 15 set. 2018.

INSTITUTE FOR ECONOMICS AND PEACE. Global Terrorism Index: Measuring and understanding the impact of terrorism. Institute for Economics and Peace, 2017. Disponível em: <http://economicsandpeace.org/reports/>. Data de acesso: 15 ago. 2018.

HAWK, J. Russia's updated Foreign Policy Concept - analysis. South Front, 2017. Disponível em: <https://southfront.org/russias-updated-foreign-policy-concept $>$. Data de acesso: 14 set. 2018 . 
HUntington, P. S. O Choque de Civilizações e a Recomposição da Ordem Mundial. Rio de Janeiro: Editora Objetiva LTDA, 1996.

KISSINGER, H. Ordem Mundial. Rio de Janeiro: Editora Objetiva LTDA, 2015.

NAPOLEONI, L. A Fênix Islamista: O Estado Islâmico e a Reconfiguração do Oriente-Médio. Rio de Janeiro: Bertrand Brasil, 2015.

PILLAR, P. R. Counterterrorism. In: Security Studies: An Introduction. London: Taylor \& Francis Group, 2008, p.376-387.

ROGERS, P. Terrorism. In: Security Studies: An Introduction. London: Taylor \& Francis Group, 2008, p. 171-184.

SPEAR, J. Counterinsurgency. In: Security Studies: An Introduction. Londres: Taylor \& Francis Group, 2008, p.389-404.

TANNO, G. A Contribuição da Escola de Copenhague aos Estudos de Segurança Internacional. Contexto Internacional, v.25, n.1, 2003, p.47-80.

WALTZ, K. O Homem, o Estado e a Guerra: uma análise teórica. São Paulo: Martins Fontes, 2004.

WENDT, A. Teoria Social da Política Internacional. Rio de Janeiro: Ed. PUC-Rio, 2014. 